Revista Docência do Ensino

Superior

v. 1,2011

Fernanda Bartolomeo Freire-Maia

UFMG

Flávio de Freitas Mattos

UFMG

João Henrique Lara do Amaral

UFMG

Mauro Henrique Nogueira G. Abreu

UFMG

Célia Regina Moreira Lanza

UFMG

Lia Silva de Castilho

UFMG

Cláudia Silami de Magalhães

UFMG

Maria de Lourdes de Andrade

Massara

UFMG

Júlio Carlos Noronha

UFMG

Alessandra Raid Carneiro

UFMG

Thiago Rodrigues Pacheco

UFMG

\section{AVALIAÇÃO DA UTILIZAÇÃO DOS MAPAS CONCEITUAIS EM DISCIPLINAS DO CURSO DE ODONTOLOGIA DA UFMG NA PERCEPÇÃO DOS ESTUDANTES}

\section{EVALUATION OF THE USE OF CONCEPTUAL MAPS IN DISCIPLINES OF THE UNDERGRADUATE COURSE IN DENTISTRY OF UFMG IN THE STUDENTS' PERCEPTION}

\section{RESUMO}

Este estudo tem como objetivo avaliar a utilização dos mapas conceituais nas Disciplinas de Clínica Integrada de Atenção Primária I, II, III, IV, V e de Odontopediatria I e II do Curso de Odontologia da Universidade Federal de Minas Gerais considerando a percepção dos estudantes do curso. As disciplinas introduziram experimentalmente a utilização dos mapas conceituais como estratégia de ensino durante o $1^{\mathrm{o}}$ semestre letivo de 2011, com diferentes abordagens, considerando a especificidade de seus conteúdos. No final do semestre, questionários para avaliação da utilização dos mapas conceituais foram distribuídos para os estudantes do curso matriculados nas disciplinas mencionadas. Entre os 196 estudantes que responderam o questionário, 69,4\% fizeram uma avaliação positiva da atividade. É importante destacar que 73\% dos estudantes mostraram-se satisfeitos quando perguntados sobre a utilização dos mapas conceituais no relato de casos clínicos. Além disso, os estudantes salientaram a aplicação dos mapas conceituais na síntese dos temas em estudo, na compreensão e articulação de conteúdos da formação e na abordagem integral dos pacientes durante o atendimento clínico. Esses resultados apontam para a necessidade de aprimoramento na utilização dos mapas conceituais, devendo a sua utilização permanecer como uma das estratégias de ensino nos próximos semestres letivos.

Palavras-Chave: Mapas conceituais. Metodologia inovadora. Aprendizagem significativa. Odontologia.

\section{ABSTRACT}

This study aims at evaluating the use of conceptual maps in the integrated primary clinical care disciplines I, II, III, IV, V and pediatric dentistry disciplines I and II from the undergraduate course of the dental school of the federal university of minas gerais, considering students' perception. The disciplines have experimentally introduced the use of conceptual maps as a teaching strategy during the first semester of 2011 with different approaches, considering the specificity of each topic. In the end of the semester questionnaires for the evaluation of the use of the conceptual maps were distributed among the students enrolled in the mentioned disciplines. Among the 196 students who answered the questionnaires, $69.4 \%$ positively evaluated the activity. It should be mentioned that $73 \%$ of the students said they were satisfied with the use of conceptual maps in reporting clinical cases. Moreover, the students highlighted the use of conceptual maps in summarizing the topics under study, understanding and articulating knowledge and providing integral care for patients. Such results point towards the need for improvement of the use of conceptual maps, while they should remain as a teaching strategy for the next semesters.

Keywords: Conceptual maps. Innovative methodology. Significant learning. Dentistry. 


\section{INTRODUÇÃO}

A aprendizagem significativa trata da relação entre a nova informação e a estrutura de conhecimento do estudante, o que ele já conhece. Essa leitura do processo de ensinoaprendizagem está baseada na contribuição do filósofo John Dewey (1859-1952) para a teoria educacional. Segundo Dewey,

a educação, como o processo através do qual modificações na disposição mental e emocional dos indivíduos são alcançadas, constitui-se numa atividade onde hipóteses sobre o que é desejável são testadas e transformações necessárias são efetivamente alcançadas (DEWEY1, 1994 apud MAMEDE, 2001, p. 58).

A afirmação de Dewey remete imediatamente às práticas pedagógicas nas salas de aulas e nas clínicas de atendimento dos cursos da educação superior na área da saúde. Até que ponto é permitido que o processo educativo aconteça em plenitude? A experiência mostra que a grande maioria dos estudantes foi treinada, mesmo antes da universidade, para uma atitude passiva na relação pedagógica. Isso é reforçado pelo processo de seleção a que são submetidos para ingressar no ensino superior. Também se esquece que, como adultos, a disposição para a aprendizagem e o desejo de aprender são condições determinantes para a aplicação nos estudos. É pouco provável que um estudante que não perceba com clareza o sentido de determinado conteúdo se aplique para compreendê-lo. O aprendizado torna-se uma tarefa difícil e termina sendo estimulado muito mais pelo seu componente avaliativo.

Com o objetivo de oferecer alguns elementos para reflexão, antes de propor um método específico de aprendizagem na formação de profissionais na área da saúde, Mamede et al. (2001, p. 88) discutem o que chamam de "um relativamente pequeno grupo de teoremas que sumarizam o estado da arte da aprendizagem". Esses princípios são apresentados neste trabalho de forma resumida.

De início, os autores anunciam como um dos pilares da psicologia cognitiva que o conhecimento "não pode ser transferido; o estudante tem que ativamente dominá-lo" (MAMEDE et al., 2001, p. 88). Para que o estudante tenha sucesso na sua empreitada é necessário um conhecimento prévio que guarde relação com o novo tema. $\mathrm{O}$ conhecimento prévio vai determinar a quantidade e a natureza das informações que

1 DEWEY, J. Democracy and Education. ILT: Digital Classics, 1994. Disponível em: <http://www.ilt.columbia.edu/ projects/digitexs/dewe/d_e>. Acesso em: set. 2001. 
serão efetivamente processadas. Para que o conhecimento prévio possibilite o aprendizado é necessário que ele seja ativado no contexto da nova informação.

Outro princípio estabelece uma relação entre a forma como o conhecimento é estruturado na memória e a menor ou maior acessibilidade no momento da sua utilização. O conhecimento está estruturado na forma de proposições constituídas de dois conceitos entre os quais se estabelece uma relação.

Outros dois princípios merecem atenção. Primeiro, ao ampliar a trama de relações entre dois conceitos, o estudante consegue uma rede de proposições com diferentes caminhos, o que facilita a recuperação do conhecimento apreendido. A esse processo dá-se o nome de elaboração da informação durante o aprendizado. O segundo princípio vincula o maior sucesso no aprendizado à motivação do aprendiz. Maior motivação implica maior tempo aplicado no aprendizado e maior aproximação dos objetivos perseguidos (MAMEDE et al., 2001).

O ensino de graduação ressente-se da dificuldade de desenvolver a aprendizagem significativa. Esse limite pode estar relacionado a uma insuficiência no aporte de informações prévias necessárias ao aprendizado, à falta de significado perceptível pelo estudante da necessidade daquele conteúdo ou ainda à ausência de oportunidade de aplicação imediata das novas informações. Se, durante a formação, o estudante não atribui significado ao aprendizado, as dificuldades de compreensão dos problemas permanecerão e é possível que entendimentos nem sempre corretos ocupem o lugar da melhor compreensão dos fenômenos. Essa questão adquire dimensões ainda mais importantes quando se pensa na formação do docente para o nível fundamental e médio. No ensino superior, correndo-se o risco de caminhar para a perda de sentido das discussões, se não se considerar como uma das origens do problema a formação dos professores da educação fundamental (ALMEIDA; MOREIRA, 2008).

Ausubel (1982) salienta a importância do conteúdo verbal da aprendizagem, enfatizando a aquisição e a retenção de saberes de forma que possuam significados. Esta assertiva, por sua vez, embasa sua teoria da "aprendizagem significativa". Para este autor, a aprendizagem não depende exclusivamente da motivação. Quando se aprende alguma coisa há uma satisfação inicial que faz surgir um desejo de continuação desta situação prazerosa. Para o autor o conhecimento não pode ser organizado de forma arbitrária e ancorado exclusivamente na memorização. Ele deve ser compreendido, ser significativamente relevante e suficientemente integrado (GOMES, 2011). Novak (1988) criou a ferramenta de aprendizagem denominada "Mapa Conceitual", que é basica- 
mente um esquema para mapear, de forma hierarquizada, os conceitos presentes na abordagem de um tema. Seu objetivo é representar relações significativas entre conceitos na forma de proposições. Estas proposições unem os conceitos por meio de palavras constituindo assim a unidade semântica. Os mapas conceituais obedecem a uma estrutura hierárquica e têm como referência o grau de generalidade e de inclusão dos conceitos. Não existem dois mapas conceituais iguais. Cada elaboração é uma em particular e, caso o mapa seja construído coletivamente, o será considerando a negociação dos diferentes pontos de vista dos componentes do grupo (COGO et al., 2009).

A avaliação dos mapas conceituais não é uma tarefa fácil, impõe uma reestruturação dos procedimentos usualmente adotados em sala de aula e aponta, como uma alternativa que pode gerar resultados positivos, a inclusão dos alunos no processo avaliativo (CORREIA et al., 2010).

Em um primeiro momento, no início da utilização dos mapas conceituais, os resultados deixam a desejar, especialmente em termos de aprofundamento e reflexão temática. Para alcançar um nível de abstração que consubstancie o pensamento crítico, é preciso um processo mais longo que provoque permanentemente os estudantes. Para que os objetivos propostos com a implantação dos mapas sejam alcançados faz-se necessário a sua utilização desde os primeiros períodos da formação, e em múltiplas situações. O mapa conceitual pode ser entendido como uma estratégia de monitoração da aprendizagem ao longo do curso, de uma disciplina ou de um conteúdo, pois além de sinalizar os conceitos apreendidos permite integrar o conhecimento novo aos conhecimentos prévios (COGO et al., 2009).

O objetivo deste trabalho é apresentar uma avaliação do emprego dos mapas conceituais na perspectiva dos estudantes do Curso de Odontologia da UFMG, matriculados nas Disciplinas de Clínica Integrada de Atenção Primária e Odontopediatria no primeiro semestre de 2011. Esses estudantes cursam disciplinas do $4^{\circ}$ ao $8^{\circ}$ períodos do curso. A implantação dos mapas conceituais foi realizada com apoio do GIZ - Rede de Desenvolvimento de Práticas de Ensino Superior, órgão vinculado à Pró-Reitoria de Graduação da UFMG, que tem como objetivo promover o aprimoramento dos métodos de ensino e a reflexão da prática docente. Foram selecionados dois estudantes monitores bolsistas entre os alunos do curso para colaborar com a implantação dos mapas conceituais. 


\section{O CENÁRIO E O PROCESSO DE IMPLANTAÇÃO DE MAPAS CONCEITUAIS}

Em resposta ao Edital de Convocação PROGRAD 02/2009, de apoio à elaboração de material didático para emprego de metodologias de ensino inovadoras na UFMG, a Faculdade de Odontologia candidatou-se com o projeto Estímulo à criação de material didático e ao emprego de metodologias inovadoras no ensino do conteúdo da atenção primária no Curso de Odontologia da UFMG. No projeto foi proposta a implantação dos mapas conceituais como instrumento para o ensino de graduação no curso.

Com a seleção do projeto os mapas conceituais foram implantados durante o primeiro semestre de 2011, no 4\% , 5 , 6 7 $^{\circ}$ e $8^{\circ}$ períodos do curso, nas Disciplinas de Clínica Integrada de Atenção Primária I, II, III, IV, V e Odontopediatria I e II. Na proposta a aplicação dos mapas foi diferenciada em cada período de acordo com as necessidades específicas de cada disciplina. Foi disponibilizada a assessoria da Rede de Desenvolvimento de Práticas de Ensino Superior da UFMG - GIZ, naquele momento, Núcleo de Apoio à Produção de Material Didático - GIZ. Em observação ao cronograma do projeto, as atividades foram iniciadas na fase de preparação, durante o $2^{\circ}$ semestre de 2010.

O Curso de Odontologia da UFMG tem na sua organização curricular a oferta do conteúdo da atenção primária em Odontologia para o adulto e a criança, sendo ele estruturante da formação profissional. O conteúdo é desenvolvido, no seu componente da atenção clínica odontológica ao adulto, do $4^{\circ}$ ao $8^{\circ}$ períodos. Para a saúde da criança são ofertadas duas disciplinas de Odontopediatria, uma no $6^{\circ}$ e outra no $7^{\circ}$ período. Embora se denomine como atenção primária, cada uma dessas atividades guarda uma especificidade, uma vez que cada uma delas incorpora diferentes dimensões e estágios do desenvolvimento dos estudantes.

Segue quadro resumo com as atividades acadêmicas, períodos do curso, temas abordados e professores responsáveis, onde foi utilizada a estratégia dos mapas conceituais. 
Quadro 1 - Atividades acadêmicas, períodos do curso, temas abordados e professores responsáveis

\begin{tabular}{|c|c|c|c|}
\hline $\begin{array}{c}\text { Atividade acadêmica/ } \\
\text { disciplina }\end{array}$ & $\begin{array}{c}\text { Período de } \\
\text { oferta }\end{array}$ & Tema & $\begin{array}{c}\text { Professor } \\
\text { responsável }\end{array}$ \\
\hline $\begin{array}{l}\text { Clínica Integrada de } \\
\text { Atenção Primária I }\end{array}$ & $4^{\mathrm{O}}$ & $\begin{array}{l}\text { Diagnóstico e decisão no tratamento } \\
\text { odontológico: duplas de estudantes } \\
\text { elaboraram mapas conceituais } \\
\text { sumarizando o processo de } \\
\text { diagnóstico e planejamento no } \\
\text { atendimento clínico. Os mapas } \\
\text { foram apresentados em grupos de } \\
\text { estudantes de um mesmo período } \\
\text { para discussão e avaliação com a } \\
\text { presença de docentes do curso. }\end{array}$ & $\begin{array}{l}\text { Flávio de Freitas } \\
\text { Mattos }\end{array}$ \\
\hline $\begin{array}{l}\text { Clínica Integrada de } \\
\text { Atenção Primária II }\end{array}$ & $5^{\circ}$ & $\begin{array}{l}\text { Decisão no tratamento da doença } \\
\text { periodontal e abordagem das lesões } \\
\text { dentárias não cariosas em adultos: } \\
\text { foram elaborados dois mapas } \\
\text { conceituais sobre os temas. }\end{array}$ & $\begin{array}{l}\text { Célia Regina } \\
\text { Moreira }\end{array}$ \\
\hline $\begin{array}{l}\text { Clínica Integrada de } \\
\text { Atenção Primária III }\end{array}$ & $6^{\circ}$ & $\begin{array}{l}\text { A utilização de antimicrobianose } \\
\text { analgésicos na prática clínica: foi } \\
\text { elaborado pelos estudantes um } \\
\text { mapa conceitual sobre o tema. }\end{array}$ & $\begin{array}{l}\text { Lia Silva de } \\
\text { Castilho }\end{array}$ \\
\hline $\begin{array}{l}\text { Clínica } \\
\text { Odontopediátrica I }\end{array}$ & $6^{\circ}$ & $\begin{array}{l}\text { 1) Tratamento endodôntico radical em } \\
\text { dentes decíduos: foram elaborados } \\
\text { pelos estudantes, em duplas, mapas } \\
\text { conceituais sobre o tema. Os mapas } \\
\text { foram entregues e avaliados pela } \\
\text { docente. }\end{array}$ & $\begin{array}{l}\text { Maria de Lourdes } \\
\text { de Andrade } \\
\text { Massara }\end{array}$ \\
\hline Atividades 1 e 2 & & $\begin{array}{l}\text { 2) Elaboração de planejamento integral } \\
\text { com casos clínicos: após seleção dos } \\
\text { casos, os estudantes elaboraram o } \\
\text { planejamento integral, na forma de } \\
\text { mapas conceituais, abordando } \\
\text { aspectos educativos, preventivos e } \\
\text { curativos. Os mapas foram } \\
\text { entregues via Moodle. Foi realizada } \\
\text { discussão dos casos com a } \\
\text { participação dos docentes. }\end{array}$ & $\begin{array}{l}\text { Fernanda } \\
\text { Bartolomeo Freire } \\
\text { Maia }\end{array}$ \\
\hline $\begin{array}{l}\text { Prática de Ensino em } \\
\text { Odontopediatria I }\end{array}$ & & $\begin{array}{l}\text { 3) Caso clínico em situação hipotética: } \\
\text { fornecidos dados de anamnese, } \\
\text { levantamento de necessidades, } \\
\text { fotografias e mapa conceitual } \\
\text { representativo da situação- } \\
\text { problema, foi solicitado o } \\
\text { planejamento integral do } \\
\text { atendimento na forma de mapa } \\
\text { conceitual. Os mapas foram } \\
\text { encaminhados via Moodle, } \\
\text { impressos e discutidos em grupo } \\
\text { sob supervisão docente. Foi } \\
\text { solicitada revisão bibliográfica para } \\
\text { embasar o plano de tratamento } \\
\text { proposto pelos estudantes. }\end{array}$ & $\begin{array}{l}\text { Fernanda } \\
\text { Bartolomeo Freire } \\
\text { Maia }\end{array}$ \\
\hline $\begin{array}{l}\text { Clínica Integrada de } \\
\text { Atenção Primária IV }\end{array}$ & $7^{\circ}$ & $\begin{array}{l}\text { 1) Urgências em Odontologia: dor de } \\
\text { origem dentária e das estruturas de } \\
\text { suporte. Foi elaborado mapa } \\
\text { conceitual sobre o tema } \\
\text { 2) Casos clínicos: grupos de oito } \\
\text { estudantes elaboraram mapas } \\
\text { conceituais apresentando os casos } \\
\text { clínicos atendidos durante o }\end{array}$ & $\begin{array}{l}\text { João Henrique Lara } \\
\text { do Amaral }\end{array}$ \\
\hline
\end{tabular}




\begin{tabular}{|c|c|c|c|}
\hline & & semestre letivo na disciplina & \\
\hline $\begin{array}{c}\text { Atividade acadêmica/ } \\
\text { disciplina }\end{array}$ & $\begin{array}{l}\text { Período de } \\
\text { oferta }\end{array}$ & Tema & $\begin{array}{l}\text { Professor } \\
\text { responsável }\end{array}$ \\
\hline $\begin{array}{l}\text { Clínica } \\
\text { Odontopediátrica II }\end{array}$ & $7^{\circ}$ & $\begin{array}{l}\text { Casos clínicos: duplas de estudantes } \\
\text { elaboraram mapas conceituais } \\
\text { apresentando as condições de saúde } \\
\text { e o atendimento clínico realizado de } \\
\text { pacientes. Os mapas foram } \\
\text { entregues impressos e realizada } \\
\text { discussão em grupo com o } \\
\text { professor orientador }\end{array}$ & $\begin{array}{l}\text { Júlio Carlos } \\
\text { Noronha }\end{array}$ \\
\hline $\begin{array}{l}\text { Clínica Integrada de } \\
\text { Atenção Primária V }\end{array}$ & $8^{\circ}$ & $\begin{array}{l}\text { Manutenção preventiva na prática } \\
\text { odontológica: duplas de estudantes } \\
\text { elaboraram mapas conceituais dos } \\
\text { casos clínicos atendidos no semestre } \\
\text { letivo, incluindo diagnóstico e } \\
\text { planejamento integral. Os } \\
\text { estudantes entregaram o trabalho } \\
\text { gravado em CD-ROM. Duas duplas } \\
\text { foram sorteadas para apresentar o } \\
\text { trabalho em data show, seguida de } \\
\text { discussão do caso }\end{array}$ & $\begin{array}{l}\text { Cláudia Silami de } \\
\text { Magalhães }\end{array}$ \\
\hline
\end{tabular}

Foi realizada capacitação dos docentes do curso diretamente envolvidos com o projeto e dos estudantes bolsistas monitores para a utilização dos mapas conceituais. A capacitação incluiu treinamento na operacionalização dos softwares CmapTools® e Xmind ${ }^{\circledR}$. Estes professores e os bolsistas assumiram a responsabilidade de capacitar, quando demandados, outros professores do curso e estudantes na utilização dos mapas conceituais. A capacitação da equipe do projeto foi realizada pelo GIZ.

O programa CmapTools® é um software desenvolvido pelo Institut for Human and Machine Cognition da The University of West Florida. Pode ser acessado gratuitamente pelo site: http://cmap.ihmc.us/download. O Programa Xmind® não estava disponível gratuitamente.

\section{METODOLOGIA}

Ao final do $1^{\circ}$ semestre de 2011 foi realizada, como de rotina, a avaliação das disciplinas. Foram incluídas na avaliação questões relativas à utilização, pelos estudantes, dos mapas conceituais. Foram distribuídos e recolhidos pelos professores questionários em meio físico. As questões versaram sobre a utilização do computador e acesso à internet, conhecimento e utilização no $1^{\circ}$ semestre de 2011 e anteriores dos mapas conceituais, nível de aprendizado na utilização dos softwares CmapTools ${ }^{\circledR}$ e $X \operatorname{mind} \AA$, satisfação na utilização dos dois modelos de mapas, primeiras impressões dos estudantes na utilização dos mapas conceituais, trabalho com os mapas em dupla ou de forma indivi- 
dual, tipo de atividade didática em que se aplicaram os mapas conceituais, dificuldades encontradas, feedback dos professores e comentários apresentados de forma livre sobre a utilização dos mapas. As informações foram organizadas em um banco de dados e a análise descritiva, realizada por meio de um programa estatístico.

\section{RESULTADOS}

São apresentadas as primeiras impressões dos estudantes na utilização dos mapas conceituais. Elas se referem, em algumas situações, à utilização dos softwares disponibilizados para a elaboração dos mapas. Outras questões dizem respeito à maior ou menor dificuldade na elaboração dos mapas, vantagens para o processo de aprendizado e potenciais na elaboração e hierarquização dos conteúdos curriculares. Uma avaliação considerando critérios de análise como a adequada conexão e representatividade dos conceitos, o uso pertinente de palavras de enlace, criatividade e a organização geral do mapa, entre outros aspectos, mostra-se de grande valia na avaliação do aprendizado do estudante (RUIZ-MORENO, 2007). Construir esse processo de avaliação é um desafio que começou a ser enfrentado pela equipe de professores que utiliza os mapas conceituais nas disciplinas do curso.

Do total de 274 estudantes de graduação matriculados, do $4^{\circ}(71), 5^{\circ}(44), 6^{\circ}$ (59), $7^{\circ}(52)$ e $8^{\circ}$ (48) períodos, retornaram respondidos 196 questionários, o que representa $71 \%$ de retorno. Desagregando por períodos do curso, retornaram 65 questionários $(91,5 \%)$ do 4 , zero do 5o, $53(89,8 \%)$ do 6o, $52(85,24 \%)$ do 7 o e $28(58,3 \%)$ do $8^{\text {o }}$ período. Não houve retorno do $5^{\circ}$ período e o $8^{\circ}$ período apresentou o menor retorno. Foram desconsiderados dois questionários do $8^{\circ}$ período por estarem incompletos. Em função de um movimento de paralisação dos funcionários técnico-administrativos em educação, não foi possível recolher os questionários respondidos pelos estudantes do $5^{\circ}$ período.

Entre os respondentes, $74 \%$ são do sexo feminino. A média das idades é de 22,6, a mediana de 22 e a moda de 21 anos. Dos 196 questionários válidos, 32,1\% pertencem a estudantes do $4^{\circ}$ período, $27 \%$ do $6^{\circ}, 25 \%$ do $7^{\circ}$ e $15,8 \%$ do $8^{\circ}$. Todos os 196 estudantes que responderam ao questionário relatam ter computador e 192 possuem internet na residência. Não conheciam o mapa conceitual 95,4\%. Relatando as expectativas iniciais durante a apresentação da proposta de trabalho com os mapas conceituais, $50 \%$ dos respondentes avaliaram, naquele momento, que seria difícil aprender a trabalhar com os mapas, $74 \%$, que a experiência não seria interessante e $12,2 \%$, que a ativi- 
dade não teria um desenvolvimento adequado. Entretanto, 93,4\% dos respondentes relatam, pelo questionário de avaliação, ter aprendido a trabalhar com os mapas conceituais.

Apesar de ter sido colocada à disposição dos estudantes a possibilidade de orientação individual na utilização dos softwares, apenas 15,8\% dos estudantes relatam ter aprendido a trabalhar com os mapas com o auxílio dos monitores bolsistas. Um dado que merece ser analisado mais detidamente, e relacionado com o anterior, é o relato de $41,8 \%$ dos que responderam ao questionário confirmando comparecimento aos plantões organizados pelos bolsistas. Nessa mesma direção, 40,3\% dos estudantes que participaram deste estudo avaliam os plantões como sem importância na aprendizagem dos mapas conceituais, 49\% relatam ter aprendido a trabalhar sozinhos e 30,6\%, ter aprendido com os colegas. Os professores pouco participaram auxiliando a aprendizagem dos mapas conceituais. A participação dos docentes aconteceu para 1,5\% dos estudantes que responderam ao questionário. O CmapTools ${ }^{\circledR}$ foi o programa mais empregado, com $44,4 \%$, seguido pelo $X \operatorname{mind} \AA$, com $42,9 \%$ dos relatos. O domínio na utilização dos dois softwares foi relatado com percentuais de 44,9\%. Não tiveram dificuldades em instalar os softwares $83,7 \%$ dos estudantes.

A plataforma Moodle foi utilizada para a entrega dos mapas aos professores por $20,9 \%$ dos estudantes. A forma impressa foi utilizada em $68,9 \%$ dos casos. Os mapas construídos pelos estudantes foram apresentados nas turmas com recursos de projeção em 17,3\% dos casos, as informações trazidas pelos mapas foram trabalhadas em grupos de discussão e nas clínicas de atendimento para 32,7\% dos estudantes e não houve apresentação para 36,2\%. Dos alunos que responderam ao questionário, 95,9\% apresentaram os trabalhos em duplas, 99\% trabalharam com casos clínicos e 73\% gostaram da experiência. Após o primeiro contato com os mapas conceituais, 34,7\% avaliam os mapas como de fácil elaboração e $25 \%$ julgam essa tarefa como difícil. Entre os respondentes, 40,8\% avaliam que os mapas conceituais ajudam na atividade de raciocínio, 20,9\% reconhecem que a ferramenta facilita o aprendizado, 42,3\% acreditam que ela ajuda a criar relações entre conceitos, e favorece a hierarquização do conhecimento para $25,5 \%$ dos respondentes. Os mapas conceituais ajudam na incorporação do conhecimento para $17,3 \%$ dos estudantes e permite focar no que é essencial em 30,6\% dos casos.

Não gostaram de trabalhar com mapas conceituais 20,9\% dos respondentes, 8,2\% julgam difícil identificar os conceitos, 22,4\% têm dificuldade em hierarquizá-los e 
37,8\% em estabelecer palavras de ligação. O relato de dificuldade geral na construção dos mapas é encontrado em 32,7\% dos casos. Apenas 30,6\% dos respondentes relatam ter recebido feedback após a entrega dos mapas conceituais. Apesar das dificuldades relatadas, 69,4\% dos estudantes esperam que os mapas conceituais sejam mantidos como estratégia de ensino e que sejam incluídos no desenvolvimento de outras disciplinas $(44,9 \%)$. Além disso, $48 \%$ consideram os mapas conceituais uma ferramenta de estudo interessante, independentemente de ser solicitada a sua utilização pelo professor.

Os mapas conceituais como ferramenta para estruturar a abordagem de casos clínicos foram bem avaliados por 73\% dos estudantes. Entre 143 estudantes que gostaram de organizar casos clínicos na forma de mapa conceitual, 65,7\% relataram que o instrumento permitiu uma visão mais integral do paciente, incluindo os determinantes sociais do processo saúde-doença, o planejamento da atenção, a abordagem educativa, preventiva e reabilitadora. Neste aspecto, os softwares de mapas conceituais permitem anexar fotos, radiografias, comentários, artigos científicos e documentos que podem enriquecer a sua utilização.

Na questão aberta, os estudantes manifestaram de forma livre as suas impressões sobre os mapas conceituais e sua utilização nas disciplinas mencionadas.

Entre as impressões positivas pode-se destacar a potência dos mapas conceituais na elaboração de sínteses dos conteúdos curriculares, proporcionando uma melhor apreensão pelo estudante. Nesse mesmo sentido, a possibilidade de hierarquização do conhecimento em conceitos permite a identificação das conexões possíveis e das relações entre eles. No campo da integralidade do cuidado especialmente, esse poder de síntese e o estabelecimento de um conjunto de ações de forma hierárquica caminham no sentido de permitir respostas mais ágeis e efetivas no atendimento das necessidades da população. $\mathrm{O}$ foco da ação profissional pode então ser orientado, quando necessário, para aspectos pontuais e determinantes das condições de saúde da população. Outro aspecto positivo facilitado pelos mapas, além da hierarquização do conhecimento, é o aprofundamento em cada conceito para melhor estabelecer sua complexa rede de conexões. Nesse esforço, ao mesmo tempo que se ganha em profundidade e no aprendizado carregado de sentido, constrói-se uma visão ampla dos fenômenos. Na saúde isso acontece enquanto o raciocínio clínico profissional ganha em agilidade, flexibilidade e profundidade.

As restrições à utilização dos mapas conceituais devem ser enfrentadas pela via da proposição de alternativas para a superação dos problemas. Alguns estudantes 
avaliam a atividade com mapas como sendo confusas e sem potencial para a incorporação de um novo conhecimento. Outros relatam que a atividade em nada ajudou na apreensão dos conteúdos e serviu apenas como ferramenta na elaboração de resumos de conteúdos já apreendidos. Houve também a sensação de um tempo perdido no processo de assimilação dos aspectos técnicos da construção dos mapas conceituais.

Essas manifestações permitem inferir que a aplicação dos mapas conceituais deve ser feita de forma cuidadosa ao longo da vida acadêmica considerando diferentes estágios de desenvolvimento do estudante, mesmo em grupos mais homogêneos. Além disso, um melhor entendimento sobre o propósito da utilização dos mapas conceituais só será alcançado se for previsto um tempo adequado para o desenvolvimento da habilidade para operacionalizar os softwares de apoio. Neste aspecto, também é importante distinguir o conceito e abordagem pedagógicas subjacentes à aplicação dos mapas conceituais dos aspectos operacionais e da sua representação física.

\section{DISCUSSÃO}

Na implantação dos mapas conceituais nas disciplinas do Curso de Odontologia da UFMG foram desenvolvidas diferentes experiências. Em algumas situações, a articulação entre o método, aqui entendido como dos mapas conceituais, e o material a ser produzido durante a atividade didática se estabeleceu de forma dinâmica por meio da definição de conceitos-chave sobre o tema estudado, seleção dos conceitos por ordem de importância e o estabelecimento das relações horizontais e verticais. Além disso, o compartilhamento dos mapas permitiu a sua complementação. Nos mapas préorganizados pela equipe didática e disponibilizados para os estudantes esperava-se alcançar a apreensão de conceitos- chave e de uma teia relacional entre eles (ANASTASIOU; ALVES, 2005).

A avaliação das atividades foi feita mediante o acompanhamento dos estudantes na prática clínica e da capacidade destes em estabelecer em situações reais a teia relacional proposta pelos mapas conceituais. Nas atividades em que a elaboração dos mapas foi feita pelos estudantes foram observados na avaliação: a clareza dos conceitos, se as relações estabelecidas são justificadas, a riqueza das ideias, criatividade na organização e se o conteúdo trabalhado está bem representado (ANASTASIOU; ALVES, 2005). Foi também observado se as relações estabelecidas nos mapas foram apreendidas pelos estudantes. 
A oportunidade de se trabalhar casos clínicos com mapas conceituais trouxe um enfoque relativamente novo e muito bem conceituado entre os estudantes. Esta experiência positiva pode ser aproveitada por outras áreas do ensino da Odontologia ainda não envolvidas com a utilização dos mapas conceituais.

Tal como no estudo de Cogo et al. (2009) a faixa etária dos alunos que responderam ao questionário corresponde àquela que experenciou, de forma intensa, o surgimento explosivo das tecnologias digitais das últimas décadas. Estes estudantes possuem uma facilidade natural na aprendizagem de novos recursos tecnológicos, não tendo que optar por novas formas de comunicação. De fato, como pontua Gomes et al. (2011), é preciso que a pessoa já possua algum conhecimento e capacidade de trabalhar com computadores e, por isso, locais com pouca infraestrutura tecnológica e baixa inclusão digital são pouco propícios para a introdução dos mapas conceituais, o que não é o caso dos estudantes da Faculdade de Odontologia da UFMG.

O alto percentual de alunos que nunca haviam trabalhado com mapas conceituais confirma o relato de Marquesi e Silveira (2008) com a mesma experiência com estudantes de Computação. Segundo os autores, os sujeitos não vivenciaram experiências pedagógicas no ensino médio que fossem apoiadas por este recurso didático. Poucas foram as experiências no ensino superior.

Ainda de forma semelhante ao estudo conduzido por Cogo et al. (2009), antes da apresentação de como trabalhar com mapas conceituais, os estudantes acreditavam que a sua execução seria muito difícil. Isso é natural, pois como assinalado por Gomes et al. (2011), inicialmente, criar um mapa conceitual depende muito do saber-fazer do indivíduo, bem como do seu conhecimento prévio para identificar conceitos importantes e estabelecer as relações que existem entre os mesmos. A capacidade alcançada por meio do exercício constante com os mapas conceituais leva a resultados mais efetivos ao longo do tempo.

O fato de que a maioria dos estudantes tenha tido a experiência em dupla com um colega é positivo e encontra suporte na literatura. Mateus e Costa (2009) relatam que a vivência da elaboração de um mapa conceitual, quando partilhada com alguém, produz um conhecimento mais generalizado e inclusivo, porque o "pensar" se torna mais diversificado.

A pouca participação dos professores no processo de desenvolvimento dos mapas conceituais no curso é preocupante. É esperado que o professor empregue a ferramenta de forma participativa e contextualizada com a finalidade de garantir que o 
aluno integre os conhecimentos e reflita sobre a sua própria estrutura cognitiva, organizando ao final a aprendizagem de forma hierárquica (MATEUS; COSTA, 2009).

Embora a aplicação dos mapas conceituais não tenha alcançado os resultados esperados, o fato de a maioria dos estudantes desejar que este recurso didático continue a ser empregado pela Faculdade de Odontologia é um ponto que retrata o sucesso da experiência e encontra eco na literatura consultada (MARQUESI; SILVEIRA, 2008; COGO et al., 2009).

O processo cognitivo nas atividades de ensino-aprendizagem apresenta particularidades dependendo em que situação ele acontece. Com base nesta assertiva, é natural que ferramentas também diversas devam ser consideradas para alavancar a construção do conhecimento por aqueles que ensinam e por aqueles que aprendem. Tendo esta linha de raciocínio por meta, Gomes et al. (2011) ponderam que no caso da educação médica o uso apenas de um único método, seja a aula expositiva, seja o aprendizado baseado em problemas, traz inúmeras limitações dependendo do perfil do estudante. Para estes autores, os debates sobre o uso de novas técnicas pedagógicas para potencializar o aprendizado devem estar sempre presentes e, portanto, o uso dos mapas conceituais pode representar mais uma possibilidade para a formação na área médica.

Pode-se afirmar que a experiência na Faculdade de Odontologia da UFMG com os mapas conceituais ultrapassou as características arbitrárias e sem propósito, típicas das metodologias tradicionais, mesmo sem o sucesso no grau esperado. Os mapas conceituais se constituíram em um meio capaz de empregar, como força geradora, conceitos subsunçores preexistentes na estrutura cognitiva do estudante, como preconizado por Mateus e Costa (2009). Ainda como relatado por Cogo et al. (2009), o acesso aos recursos computacionais na própria residência permitiu que os estudantes empregassem mais frequentemente os mapas conceituais como instrumento de estudo. Reforça o potencial de utilização das tecnologias educacionais o fato de a educação à distância ser valorizada pela escola. Neste campo a Faculdade de Odontologia da UFMG ainda tem um caminho a percorrer.

\section{CONCLUSÃO}

A utilização dos mapas conceituais em disciplinas do Curso de Odontologia da UFMG foi avaliada de forma geral como uma experiência positiva, o que autoriza a sua manutenção como instrumento de organização do conhecimento e ensino a ser mantido nos 
próximos semestres. É necessário que o curso avance nos processos de avaliação dos mapas conceituais e no retorno efetivo para o ensino de graduação. A aplicação dos mapas conceituais deve ser incentivada desde o início do curso, dependendo em parte dessa iniciativa o alcance para a formação profissional do potencial contido nesta ferramenta pedagógica.

\section{REFERÊNCIAS}

ALMEIDA, Voltaire de O.; MOREIRA, Marco A. Mapas conceituais no auxílio à aprendizagem significativa de conceitos da óptica física. Revista Brasileira de Ensino de Física, v. 30, n. 4, p. 4403-1-4403-7, fev. 2008.

ANASTASIOU, Léa das Graças Camargos; ALVES, Leonir Pessate. Estratégias de Ensinagem. In: ANASTASIOU, Léa das Graças Camargos; ALVES, Leonir Pessate. Processos de ensinagem na universidade: pressupostos para as estratégias de trabalho em aula. 5. ed. Joinville: Univille, 2005.

AUSUBEL, David Paul. A aprendizagem significativa: a teoria de David Ausubel. São Paulo: Moraes, 1982.

COGO, Ana Luísa Petersen; PEDRO, Eva Néri Rubim; SILVA, Ana Paula Scheffer; SPECHT, Andréia Martins. Avaliação de mapas conceituais elaborados por estudantes de enfermagem com o apoio de software. Texto Contexto Enferm, v. 18, n. 3, p. 482488, jul.-set. 2009.

CORREIA, Paulo Rogério Miranda; SILVA, Amanda Cristina; ROMANO JUNIOR, Jerson Geraldo. Mapas conceituais como ferramenta de avaliação na sala de aula. Revista Brasileira de Ensino de Física, v. 32, n. 4, p. 4402-1-4402-8, fev. 2010.

GOMES, Andréia Patrícia; DIAS-COELHO, Udson Chandler; CAVALHEIRO, Priscila de Oliveira; SIQUEIRA-BATISTA, Rodrigo. O papel dos mapas conceituais na educação médica. Revista Brasileira de Educação Médica, v. 35, n. 2, p. 275-282, 2011.

MAMEDE, S. et al. Aprendizagem baseada em problemas. Fortaleza: Hucitec, 2001. 232 p.

MARQUESI, André Luis; SILVEIRA, Ismar Frango. Mapas conceituais aplicados à seleção e organização de objetos de aprendizagem para disciplinas de pré-cálculo em cursos de Computação e Informática. In: CONGRESSO DA SOCIEDADE BRASILEIRA DE COMPUTAÇÃO, WEI - Workshop sobre Educação em Computação, 28., 2008, Belém do Pará. Anais eletrônicos... Belém do Pará: SBC, 2008. p. 137-143. Disponível em: <http://www.prodepa.gov.br/sbc2008/anais/pdf/arq0114.pdf>. Acesso em: 11 set. 2011.

MATEUS, Wagner de Deus; COSTA, Luana Monteiro. A utilização de mapas conceituais como recurso didático no ensino de ciências naturais. Revista Eletrônica de Ciências da Educação, Campo Largo, v. 8, n. 2, nov. 2009.

NEVES, Dulce Amélia de Brito. Meta aprendizagem e Ciência da Informação: uma reflexão sobre o ato de aprender a aprender. Perspectivas em Ciência da Informação, v. 12, n. 3, p. 116-128, set./dez. 2007.

NOVAK, Joseph. Teoría y pratica de la educación. Madrid: Alianza, 1998. 
RUIZ-MORENO, Lidia; SONZOGNO, Maria Cecília; BATISTA, Sylvia Helena da Silva; BATISTA, Nildo Alves. Mapa conceitual: Ensaiando critérios de análise. Ciênc. \& educ., v. 13, n. 3, p. 453-463, set.-dez. 2007. Disponível em: <http://www.scielo.br/pdf/ciedu/v13n3/a12v13n3.pdf>. Acesso em: 11 set. 2011. 